\title{
JASA PENCARIAN KOS DAN DELIVERY LAUNDRY (MY TRAVEL ROOM ++) BERBASIS ANDROID DI KABUPATEN KUDUS
}

\author{
Yusiana Rahma \\ Fakultas Teknik, Program Studi Sistem Informasi \\ Universitas Muria Kudus \\ Email: yusianarahma30@gmail.com \\ Arsya Yoga Pratama \\ Fakultas Teknik, Program Studi Sistem Informasi \\ Universitas Muria Kudus \\ Email: 201553011@std.umk.ac.id \\ Fita Choiyanti \\ Fakultas Teknik, Program Studi Sistem Informasi \\ Universitas Muria Kudus \\ Email: fitachoiyanti@gmail.com
}

\begin{abstract}
ABSTRAK
Jurnal ini merupakan publikasi dari program kompetisi bisnis Indonesia yang telah dilakukan yang berhubungan dengan pencarian kos serta delivery laundry. Program tersebut sebagai upaya untuk membantu penyewa kos mengetahui infomasi alamat kos secara tepat dan cepat khususnya di Kabupaten Kudus dan mengoptimalkan bisnis laundry yang sedang berjalan. Hasil dari perancangan ini adalah Sistem Informasi yang menyajikan hasil analisa dan rancangan yang dituangkan dalam diagram $U M L$ (Unified Modeling Language) yang terdiri dari UseCase dan Activity Diagram.Didalam jurnal ini akan menyarankan untuk dapat membuat sebuah sistem yang dapat mempermudah masyarakat dalam pemberian informasi rumah kos untuk pendatang maupun masyarakat lokal. Hasil dari penelitian ini merupakan salah satu solusi yang dapat digunakan dalam menangani permasalahan di Kabupaten Kudus dengan membuat bisnis startup My Travel Room ++. My Travel Room ++ adalah suatu sistem aplikasi pencarian kos berbasis Android yang berfungsi untuk pemberian informasi mengenai lokasi kos yang berada di kabupaten kudus serta melayani jasa laundry dengan cara delivery menggunakan aplikasi. Keunggulan aplikasi ini sudah menggunakan teknologi GIS (Geographic Information System).
\end{abstract}

Kata kunci: kos, laundry, my travel room++, android, UML, GIS.

\begin{abstract}
This journal is a publication of the competition business Indonesia that has been done related search boarding and delivery laundry. The program is an effort to help the renter knowing the exact and fast information of the boarding address, especially in Kudus District and optimizing the ongoing laundry business.The results of this design are the Information System that presents the results of analysis and design as outlined in the diagramUML (Unified Modeling Language)consisting of UseCase and Activity Diagram. In this journal, it will be suggested to create a system that can facilitate the community in providing information on boarding houses for migrants and local communities. The results of this research are one solution that can be used in handling problems in Kabupaten Kudus by creating business applicationsMy Travel Romm++. My Travel Room++ is system aplication public complent based android that serves to provide information about the location of the kos located in the holy district and serve laundry services by way of delivery using the application Excellence applications produced on the basis of GIS (Geographic Information System).
\end{abstract}

Keywords: the exact, laundry, my travel room++ , android, UML, GIS.

\section{PENDAHULUAN}

Rumah kost lebih akrab digunakan sebagai domilisi, karena kebanyakan rumah kos disewa dalam jangka waktu yang cukup lama dari pada hotel atau penginapan yang menggunakan hitungan hari [1]. Kudus merupakan salah satu kota industri yang memiliki pabrik-pabrik besar nasional serta juga terdapat 
beberapa perguruan tinggi yang mahasiswanya berasal dari Kudus sendiri dan kota-kota disekitarnya, hal ini menyebabkan jumlah penduduk di kabupaten Kudus semakin meningkat. Pendataan serta pengawasan rumah kos di kabupaten Kudus diatur dalam Peraturan Daerah Kabupaten Kudus Nomor 15 Tahun 2010 yang menyatakan bahwa rumah kos harus mendapatkan izin dari Dinas Pariwisata serta akan dikenakan pajak sesuai dengan pasal III peraturan daerah yakni rumah kos dengan jumlah kamar lebih dari sepuluh, sedangkan untuk jumlah kamar dibawah sepuluh tidak dikenakan pajak. Ditengah globalisasi saat ini dengan berbagai macam teknologi yang sangat pesat banyak sekali terciptanya alat-alat untuk membantu masyarakat menyelesaikan persoalan dengan mudah. Salah satu teknologi untuk membantu masayarakat dalam menemukan lokasi adalah GPS. GPS (Global Positioning System)adalah sistem untuk menentukan posisi dan navigasi secara global dengan menggunakan satelit. GPS dapat memberikan informasi tentang posisi, kecepatan, dan waktu secara cepat, akurat, murah, dimana saja bumi ini pada setiap saat tanpa tergantung cuaca [2]. Teknologi GPS saat ini sudah ada di dalam fitur yang terdapat pada gadget smartphone android. Teknologi GPS biasa digunakan untuk menentukan lokasi dengan akurat.

Berdasarkan kondisi yang berada di kabupaten Kudus mengenai banyaknya pendatang baru dari luar kota dan dengan adanya teknologi GPS yang terdapat pada teknologi android, Tim kami ingin mengaplikasikan teknologi tersebut sebagai jasa usaha bagi kami dengan keunggulan agar bisa bermanfaat dan mempermudah pihak penyewa kost dan pengelola kost untuk mengelola dan mengetahui informasi mengenai rumah kos denganmenggunakan teknologi GPS untuk menentukan lokasi rumah kos secara cepat dan tepat. Manfaat yang diperoleh adanya sistem ini adalah penyewa kos atau pengguna sistem dapat dengan mudah melakukan pencarian kos dengan keakuratan lokasi rumah kos. Pada aplikasi ini terdapat kelebihan yaitu dilengkapi dengan fitur delivery laundry yang akan memberikan kemudahan dalam mencuci pakaian sehingga waktu yang dimiliki dapat optimal.

\section{METODOLOGI PENELITIAN}

Dalam aplikasi My Travelroom ++ ini pendekatan yang digunakan untuk pengembangan sistem dalam penelitian ini adalah prototype. Pendekatan prototype digunakan untuk mempercepat implementasi beberapa bagian dari sistem selama atau sebelum fase persyaratan. Desain prototipe, dengan cepat dievaluasi oleh pelanggan / pengguna dan hasil evaluasinya digunakan untuk memperbaiki perangkat lunak yang dikembangkan [3]. Menggunakan metode pengembangan UML yaitu alat untuk merinci sistem perangkat lunak yang mencakup diagram standar untuk mendefinisikan, menggambarkan dan secara visual memetakan atau memodelkan desain dan struktur sistem perangkat lunak. Diagram UML terdiri dari diagram use case, diagram kelas, diagram sekuence, diagram statechart, diagram aktivitas, diagram komponen, dan diagram deployment [4]. Dalam langkah pembuatan aplikasi tersebut memiliki 4 tahap yaitu Pengumpulan data, kedua Identifikasi kebutuhan system, ketiga desain pelaksanaan sistem, dan keempat yaitu impelementasi system.

Dalam langkah pengumpulan data ini, pertama-tama melakukan pengamatan atau observasi dengan mengamati proses terjadinya pencarian kos di kabupaten Kudus dengan mencari referensi teknologi untuk mengetahui cara mengimplementasikan sebuah data dengan memanfaatkan teknologi basis data dan teknologi GPS dalam smartphone android untuk membuat aplikasi My Travelroom agar dapat lebih valid dalam menyajikan informasi bagi penggunanya.

Selanjutnya langkah kedua menganalisa solusi atas masalah yang terjadi yaitu masyarakat kesulitan dalam melakukan pencarian kos dan laundry di Kabupaten Kudus. Adapun sebagai data utama dalam pembuatan Aplikasi My Travelroom ++ yang diperlukan adalah Data penyewa kos, data kos, data pemilik kos dan data pelanggan laundry.

Dalam langkah desain pelaksanaan penelitian dengan melakukan perancangan desain terhadap sistem. Memiliki beberapa urutan yaitu dengan merancang desain sistem yang akan kita buat, membuat konsep desain sistem, dan membuat desain sistem yang akan dibuat secara rinci.

Pada langkah implementasi penelitian akan menganaisa prototype sistem serta fitur-fitur dalam aplikasi ini. Adapun prototype dari aplikasi adalah kebutuhan hardware dan software. Kebutuhan Hardware dalam sistem terdiri dari Smartphone Android Samsung J7 Prime, Flashdisk 16 GB, 2 buah mouse. Adapun kebutuhan software dalam sistem adalah Windows 10,Andoid studio versi 2.1.2, Java Development kit (JDK),Android SDK, ADT (Android development tools). Fitur yang ada dalam sistem ini ialah dapat melihat kos keberadaan kos di Kabupaten Kudus dengan memanfaatkan teknologi GPS yang berada pada smartphone android, serta dapat mengirimkan lokasi keberadaan penewa untuk dapat melakukan delivery laundry. 


\section{HASIL DAN PEMBAHASAN}

Berdasarkan hasil pengamatan terhadap lingkungan sekitar di daerah kabupaten Kudus, diketahui bahwa masih banyak pendatang baru yang memerlukan informasi mengenai letak rumah kos yang berada di daerah Kudus. Bisnis aplikasi My Travel Room selain untuk meningkatkan usaha jasa delivery laundry, bisnis ini juga akan meningkatkan pendapatan pemilik kos .

Sistem dari aplikasi My Travel Room++ ini akan tergambar alur prosesnya melalui usecase diagram. Usecase adalah teknik untuk merekam persyaratan fungsional sebuah sistem. Use Case mendeskripsikan interaksi tipikal antara para pengguna sistem dengan sistem itu sendiri, dengan memberi sebuah narasi tentang bagaimana sistem tersebut digunakan. Use Case Diagram menampilkan aktor mana yang menggunakan Use Case mana, Use Casemana yang memasukkan use case lain dan hubungan antara aktor dan Use Case [5]. Penggambaran perancangan Use Case aplikasi My Travelroom++ akan ditampilkan pada gambar 2 .

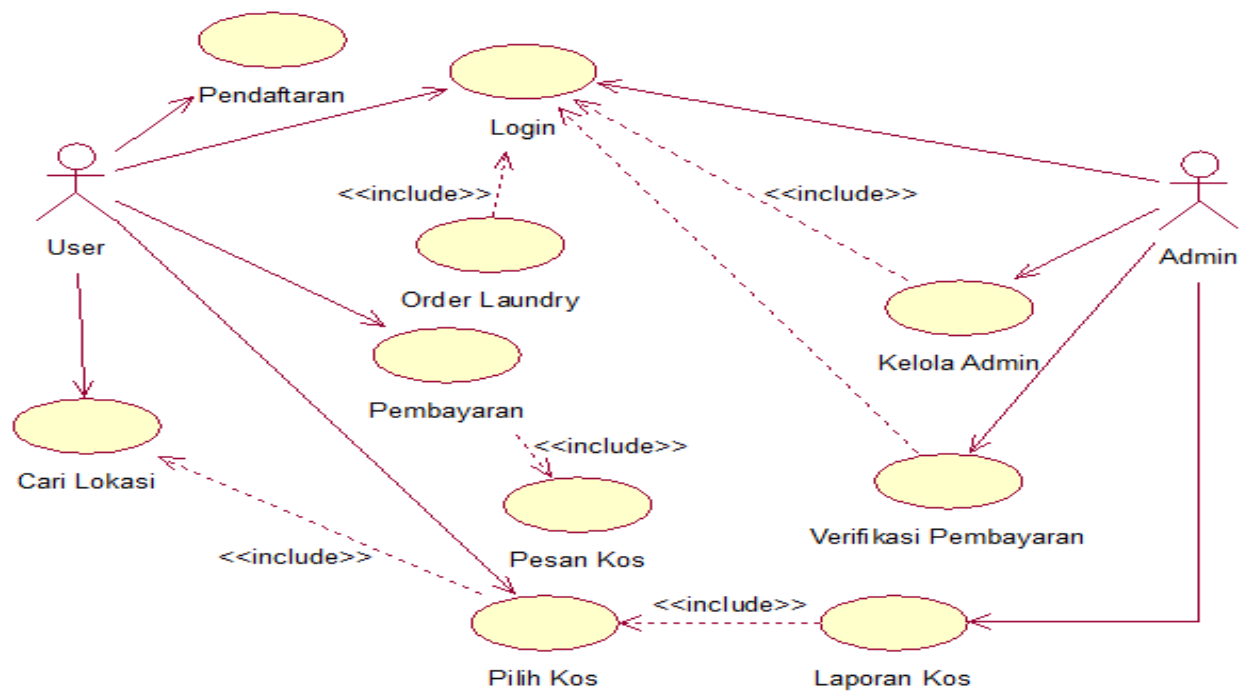

Gambar 7. Usecase Diagram Sistem

Desain konseptual lain yang dihasilkan adalah diagram aktifitas, salah satunya yang ditunjukkan pada gambar 3. Gambar 3 menunjukkan diagram aktifitas dari aktor penyewa kos saat melakukan aktifitas pendaftaran aplikasi untuk dapat memesan kos di kabupaten Kudus. Diagram Aktifitas adalah tampilan grafis yang menjelaskan proses operasional dan hubungan sebab akibat yang digunakan di dalam setiap tahapan sistem [6]. Berikut adalah tampilan alur activity diagram system dari aplikasi terlihat pada gambar 3 . 


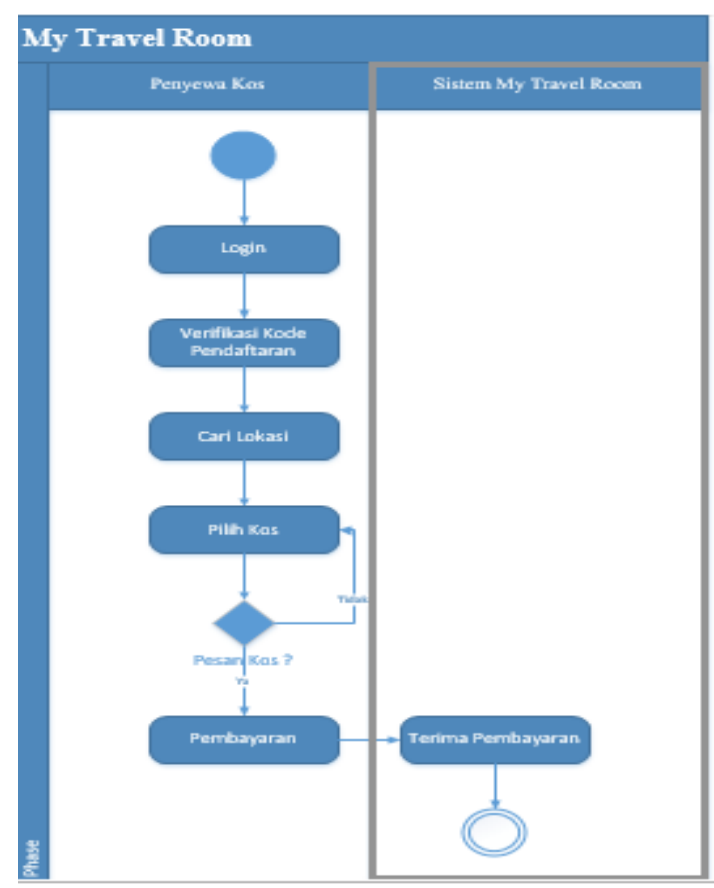

\section{Gambar 8. Activity Diagram Sistem Pendaftaran}

Hasil tampilan antarmuka dari sistem apikasi pencarian kos dan delivery laundry di kabupaten Kudus ditunjukkan sebagai berikut. Gambar 4 ini menunjukkan tampilan login dari aplikasi. Di tampilan login berikut ada 2 jenis login yaitu login untuk user atau penyewa kos dan login untuk pemilik kos. Berikut adalah tampilan desain login sistem dari aplikasi terlihat pada gambar 4.

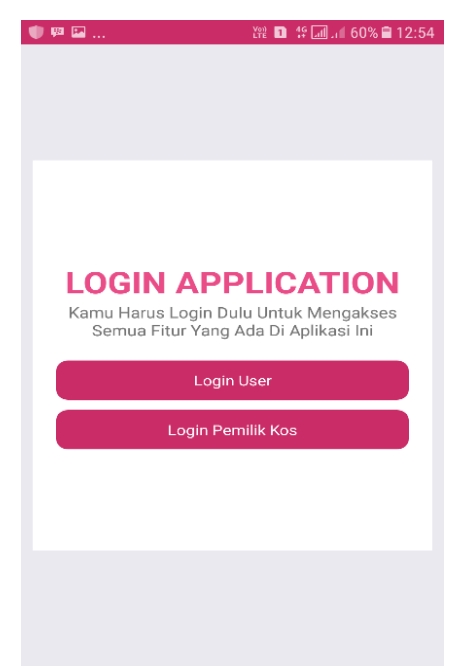

\section{Gambar 9. Desain Login Aplikasi My Travelroom ++}

Dalam gambar 5 menunjukkan tampilan saat akan memasukkan nomor hp anda. Nomor hp ini berguna untuk melanjutkan aplikasi My Travel Room++ atau login aplikasi untuk user penyewa dan pemili kos yang akan bergabung. Berikut adalah tampilan desain input nomor telepon dari aplikasi terlihat pada gambar 5 . 


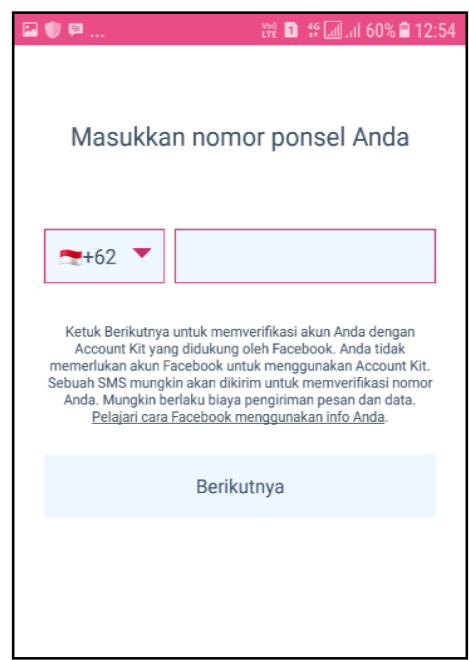

\section{Gambar 10. Desain Input Nomor HP Pada Aplikasi My Travel Room}

Pada gambar 6 menunjukkan tampilan saat akan memverifikasi kode yang dikirimkan lewat nomor handphone yang sudah dimasukkan sebelumnya. Kode verifikasi ini berjumlah 6 digit, digunakan verifikasi nomor handphone agar dapat mengetahui dengan jelas data dari penyewa atau pemilik kos. Berikut adalah tampilan desain verifikasi dari aplikasi terlihat pada gambar 6.

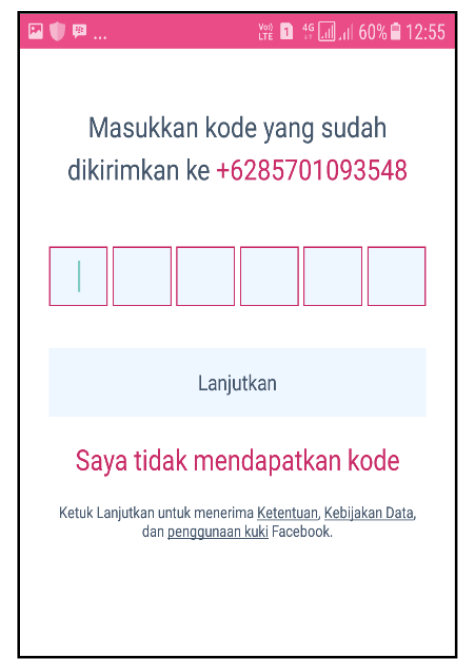

\section{Gambar 11. Desain Verifikasi No Telepon}

Dalam gambar 7 menunjukkan fitur lokasi maps agar penyewa bisa mengetahui titik lokasi kos yang ada di kabupaten kudus dengan memanfaatkan teknologi GIS (Geographic Information System). Berikut adalah tampilan desain lokasi sistem dari aplikasi terlihat pada gambar 7. 


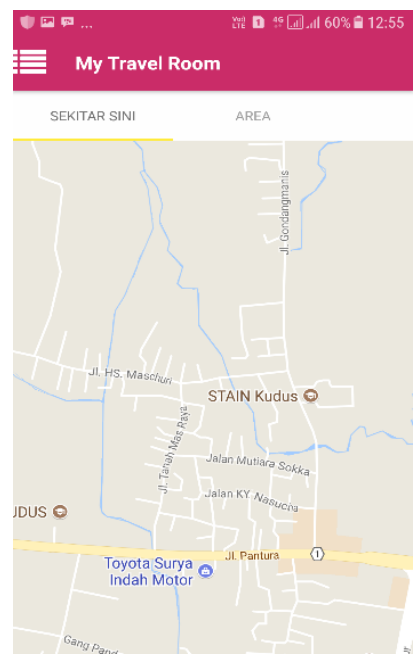

\section{Gambar 7. Desain Lokasi Pada Aplikasi My Travel Room}

Pada gambar 8 menunjukkan menu yang ada pada aplikasi My Travel Room, menu ini terdapat saat login sebagai user atau penyewa kos. Terdapat menu chatting untuk berkomunikasi dengan pemilik kos, laundry untuk delivery laundry, dan pembayaran untuk melihat pembayaran yang pending. Berikut adalah tampilan menu dari aplikasi terlihat pada gambar 8 .

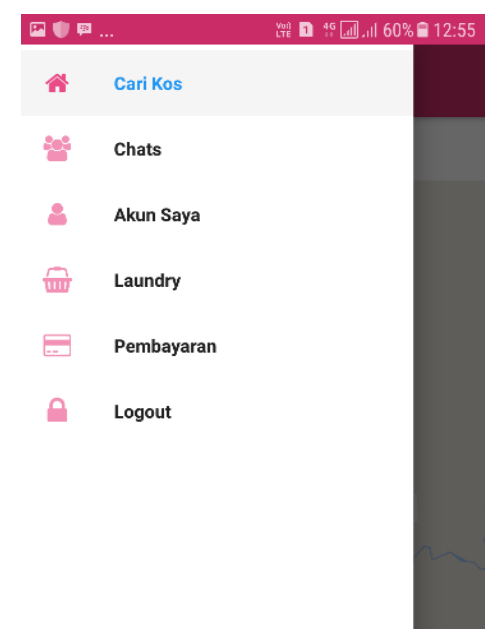

\section{Gambar 8. Desain Tampilan Menu Pada Aplikasi My Travel Room}

Pada gambar 9 menunjukkan tampilan saat akan order Laundry. Di tampilan ini user atau penyewa kos harus mengisikan nama, alamat dan catatan serta pilihan laundry yang akan di order. Fitur laundry disertai dengan GPS untuk mendeteksi lokasi pelanggan. Berikut adalah tampilan desain menu laundry dari aplikasi terlihat pada gambar 9. 


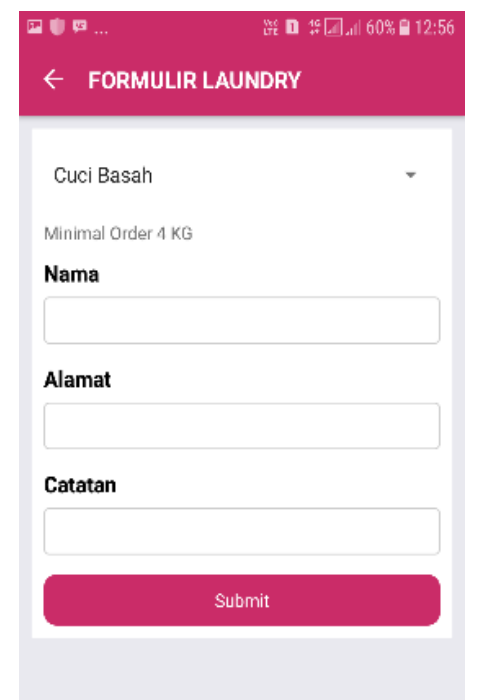

\section{Gambar 9. Desain Tampilan Menu Laundry pada Aplikasi My Travel Room}

Pada gambar 10 menunjukkan tampilan dari pihak pemilik kos. Di tampilan ini pemilik kos dapat menambahkan informasi mengenai kos mereka disertai dengan foto kos yang dimiliki. Serta terdapat point dari pembayaran oleh penyewa dan sewaktu-waktu dapat di payout. Berikut adalah tampilan menu tambah kos dari aplikasi terlihat pada gambar 10.
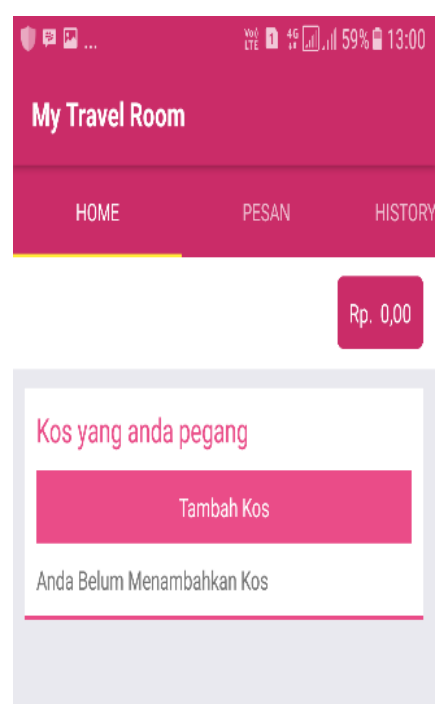

\section{Gambar 10. Desain Tampilan Menu Tambah Kos di Aplikasi My Travel Room++}

Pada gambar 11 menunjukkan menu profil dari pemilik kos. Menu ini berguna untuk memasukkan informasi mengenai pemilik kos agar dari pihak penyewa kos bisa mengetahui rekening pembayarannya. Berikut adalah tampilan menu profil dari aplikasi terlihat pada gambar 11. 


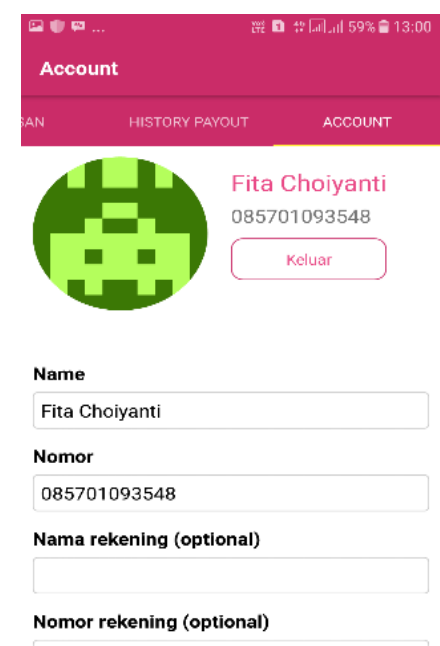

\section{Gambar 11. Desain Tampilan Menu Profil di Aplikasi My Travel Room++}

\section{KESIMPULAN}

Maksud dan tujuan My Travel Room untuk membuat system pencarian kos dan delivery laundry di kabupaten kudus. Manfaat yang diperoleh adanya sistem ini adalah penyewa kosdapat dengan mudah melakukan pencarian dan pemesanan kos dengan keakuratan lokasi yang disediakan. Pada aplikasi ini terdapat kelebihan yaitu dengan adanya fitur laundry untuk melayani jasa laundry dengan cara delivery atau menjemput baju yang akan dilaundry.

\section{UCAPAN TERIMA KASIH}

Terima kasih kepada Kementerian Riset, Teknologi, dan Pendidikan Tinggi Republik Indonesia yang telah membiayai penelitian ini melalui program kreativitas mahasiswa bidang karsa cipta.

\section{DAFTAR PUSTAKA}

[1] Andry Rachmadi. 2013. "Sistem Informasi Rumah Kost Berbasis Web di Yogyakarta". Yogyakarta,Universitas Islam Sunan Kalijaga.

[2] Abidin, H. (2007). Penentuan Posisi dengan GPS dan Aplikasinya. Jakarta: PT. Pradnya Pramita.

[3] Tiwari, Vinay. 2010. "Some Observations On Open Source Software Development On Software Engineering Perspectives". International Journal of Computer Science \& Information Technology (IJCSIT) 2. 6, 113-125.

[4] Lee, Sunguk. 2012. "Unified Modeling Language (UML) for Database Systems and Computer Applications". International Journal of Database Theory and Application 5. 1, 157-164.

[5] Fowler, Martin. 2005. UML Distilled Edisi 3, Yogyakarta: Andi.

[6] Mallick, Bipsha., and Das, Nilanjan. 2013. "An Approach to Extended Class Diagram Model of UML for Object Oriented Software Design". International Journal of Innovative Technology \& Adaptive Management (IJITAM) 1. 2. 